\title{
Neosuture formation after endoscope-assisted craniosynostosis repair
}

\author{
Afshin Salehi, MD, MS, ${ }^{1}$ Katherine Ott, BA, ${ }^{1}$ Gary B. Skolnick, BS, ${ }^{2}$ Dennis C. Nguyen, MD, ${ }^{2}$ \\ Sybill D. Naidoo, PhD, RN, CPNP, ${ }^{2}$ Alex A. Kane, MD, ${ }^{3}$ Albert S. Woo, MD, ${ }^{2}$ Kamlesh B. Patel, MD, ${ }^{2}$ \\ and Matthew D. Smyth, MD1
}

Departments of ${ }^{1}$ Neurological Surgery and ${ }^{2}$ Plastic and Reconstructive Surgery, Washington University School of Medicine, St. Louis, Missouri; and ${ }^{3}$ Department of Plastic Surgery, University of Texas Southwestern Medical Center, Dallas, Texas

OBJECTIVE The goal of this study was to identify the rate of neosuture formation in patients with craniosynostosis treated with endoscope-assisted strip craniectomy and investigate whether neosuture formation in sagittal craniosynostosis has an effect on postoperative calvarial shape.

METHODS The authors retrospectively reviewed 166 cases of nonsyndromic craniosynostosis that underwent endoscope-assisted repair between 2006 and 2014. Preoperative and 1-year postoperative head CT scans were evaluated, and the rate of neosuture formation was calculated. Three-dimensional reconstructions of the $\mathrm{CT}$ data were used to measure cephalic index $(\mathrm{Cl})$ (ratio of head width and length) of patients with sagittal synostosis. Regression analysis was used to calculate significant differences between patients with and without neosuture accounting for age at surgery and preoperative $\mathrm{Cl}$.

RESULTS Review of 96 patients revealed that some degree of neosuture development occurred in 23 patients (23.9\%): 16 sagittal, 2 bilateral coronal, 4 unilateral coronal, and 1 lambdoid synostosis. Complete neosuture formation was seen in 14 of those 23 patients ( 9 of 16 sagittal, 1 of 2 bilateral coronal, 3 of 4 unilateral coronal, and 1 of 1 lambdoid). Mean pre- and postoperative $\mathrm{Cl}$ in the complete sagittal neosuture group was $67.4 \%$ and $75.5 \%$, respectively, and in the nonneosuture group was $69.8 \%$ and $74.4 \%$, respectively. There was no statistically significant difference in the $\mathrm{Cl}$ between the neosuture and fused suture groups preoperatively or 17 months postoperatively in patients with sagittal synostosis.

CONCLUSIONS Neosuture development can occur after endoscope-assisted strip craniectomy and molding helmet therapy for patients with craniosynostosis. Although the authors did not detect a significant difference in calvarial shape postoperatively in the group with sagittal synostosis, the relevance of neosuture formation remains to be determined. Further studies are required to discover long-term outcomes comparing patients with and without neosuture formation. http://thejns.org/doi/abs/10.3171/2016.2.PEDS15231

KEY WORDS neosuture; sagittal craniosynostosis; scaphocephaly; endoscopy; strip craniectomy; suture re-formation; craniofacial

$\mathrm{T}$ He pathological process of abnormal fusion of the sutural articulations of the cranium is referred to as craniosynostosis. This occurs in 1 per 2000-2500 live births worldwide. ${ }^{7,9,21}$ Craniosynostosis is associated with more than 100 syndromes but occurs most often as an isolated condition. Among the nonsyndromic cases, sagittal synostosis is the most frequently occurring type of synostosis observed, comprising about $40 \%-55 \%$ of the cases. ${ }^{6}$ To prevent the associated complications of craniosynostosis, namely chronically elevated intracranial pres- sure and a dysmorphic appearance of the skull, surgical procedures have been performed since the 1890s (when strip craniectomy was introduced) ${ }^{8}$ Since then, multiple repair techniques have been advocated including total calvarial vault remodeling and endoscope-assisted methods. ${ }^{4}$ However, despite the increasing adoption of this technique, follow-up studies evaluating outcomes of surgically corrected synostotic sutures are lacking. In isolated cases, there have been reports of re-formation of normalappearing sutures (neosuture) after surgical correction of 
the craniosynostosis.$^{1,5,17,20}$ To the best of our knowledge, only 1 study has reported the incidence of neosuture formation after endoscope-assisted repair of unilateral coronal craniosynostosis. ${ }^{17}$ Moreover, the effect of neosuture formation on calvarial shape or morphological improvement has not been quantitatively investigated.

\section{Methods}

\section{Surgical Technique}

The endoscopic surgery was performed as previously described. ${ }^{19}$ Briefly, for sagittal synostosis, the patient is positioned in a prone sphinx position. Two incisions are made: one just posterior to the anterior fontanel and the other just anterior to the lambda. After subgaleal dissection, transverse osteotomies are made that are connected to the anterior fontanel and lambda with Mayo scissors or rongeurs. Next, with the aid of a $30^{\circ}$ rigid endoscope, the epidural space is dissected away from the overlying bone, and a craniectomy is performed behind the coronal sutures and in front of the lambdoid sutures. Between 2006 and 2012 , our "wide-vertex" craniectomy was $4-5 \mathrm{~cm}$ in width and was performed in conjunction with wedge osteotomies behind the coronal sutures and in front of the lambdoid sutures. In early 2013, we transitioned to "narrow strip" craniectomy (2-3 cm in width) without wedge osteotomies. Hemostasis is achieved by direct visualization or using the endoscope with the use of a suction-cautery device. The skin is closed using absorbable suture. Postoperatively, the patient is observed on the ward overnight, and in almost all cases discharged on Day 1. On Days 1-5, the patient is fitted for his or her first helmet, which is worn for about 6-9 months, until the patient reaches about 1 year of age. All patients receive a 3D, low-radiation protocol head CT scan as an outpatient at approximately 1 year after the operation. Metopic and coronal suturectomies are performed in the supine position using similar techniques,,$^{16}$ and lambdoid suturectomies are performed in the prone position. These suturectomies (1 cm wide) are each performed with a single $2-\mathrm{cm}$ incision based in the center of the affected suture.

\section{Study Method}

Appropriate institutional review board approval was obtained. A total of 166 cases involving endoscope-assisted nonsyndromic craniosynostosis reconstructions were reviewed retrospectively. All procedures were performed at St. Louis Children's Hospital by a single neurosurgeon (M.D.S.) and 1 of 3 craniofacial plastic surgeons (A.A.K., A.S.W., K.B.P.). Cases were categorized based on the mor- phology of the synostotic suture. Morphologies observed included sagittal, unicoronal, bicoronal, lambdoid, and metopic. The metopic cases were excluded from our analysis due to their unique early physiological suture closure. CT scans performed more than 1 year postoperatively were available for review in 96 of the 166 cases. These 96 cases were selected for further analysis. All available preoperative and postoperative head CT 3D reconstructions were reviewed, and individuals who developed neosutures were identified (Table 1).

Neosutures were defined as postsurgical re-formation of anatomically normal-appearing sutures. Neosutures were identified independently by 2 observers and subsequently put to a vote by the other coauthors. Patients who developed a neosuture were divided into 2 groups: those with a complete neosuture and those with an incomplete neosuture. Complete neosuture was defined as the postsurgical development of anatomically normal-appearing neosutures that spanned the entire length of the said suture. In contrast, incomplete neosutures were defined as anatomically normal-appearing neosutures that did not encompass the entire length of the suture; they either had areas of bone defect, noted as open gaps, or had partial areas of fused bone. Images were reviewed in detail, and cephalic indices (CIs) were calculated for the sagittal neosuture cases, as well as the age-matched control cases from the same series of patients who underwent the same procedure but did not develop a neosuture.

The CIs before surgery and 1 year after surgery were calculated for the sagittal cases as follows: CT data were evaluated using Analyze 11.0 (Mayo Clinic), a validated and reliable technique to measure the anterior-posterior length and biparietal width of the skull. Using the 3D volume render tool, reconstructed volumes were oriented to the Frankfort horizontal plane. The skull was isolated using thresholding and connected component analysis to remove extraneous artifacts and/or tissues (e.g., auricles). Both diameters were measured from a vertex view..$^{14}$ The CI was calculated as the ratio of the biparietal diameter to the anterior-posterior diameter.

Linear regression analysis was performed with postoperative $\mathrm{CI}$ as the dependent variable and presence of neosuture, preoperative CI, and age at surgery as forced entry covariates. Significance was predefined as $p<0.05$. All statistical calculations were performed using SPSS version 22 (IBM).

\section{Results}

The charts for 166 cases of endoscope-assisted cra-

TABLE 1. Rate of neosuture development in 96 endoscopic cases with postoperative CT scans available for review

\begin{tabular}{|c|c|c|c|c|c|}
\hline $\begin{array}{l}\text { Morphology of } \\
\text { Synostosis }\end{array}$ & $\begin{array}{c}\text { Mean Age at } \\
\text { Op (mos) }\end{array}$ & $\begin{array}{c}\text { Mean Age at } \\
\text { Postop CT (mos) }\end{array}$ & $\begin{array}{c}\text { No. of Cases w/ } \\
\text { Available Postop CT }\end{array}$ & $\begin{array}{l}\text { No. of Neosutures on } \\
\text { Postop CT* }\end{array}$ & $\begin{array}{l}\text { Rate of Neosuture } \\
\text { Development (\%) }\end{array}$ \\
\hline Sagittal & 3.3 & 16.2 & 73 & 16 & 22 \\
\hline Unicoronal & 3.0 & 28.0 & 11 & 4 & 36 \\
\hline Bicoronal & 3.3 & 18.7 & 7 & 2 & 29 \\
\hline Lambdoid & 5.9 & 13.3 & 5 & 1 & 20 \\
\hline Total & & & 96 & 23 & 24 \\
\hline
\end{tabular}

\footnotetext{
* Values include complete and incomplete neosutures.
} 
niosynostosis repair were reviewed. All procedures were performed at St. Louis Children's Hospital between October 2006 and June 2014 in children 7 months of age and younger, with the majority being younger than 4 months of age. The breakdown of the different types of synostosis was as follows: the most commonly found was sagittal $(\mathrm{n}=108,65 \%)$, followed by unicoronal $(\mathrm{n}=17,10 \%)$, bicoronal $(\mathrm{n}=9,5 \%)$, lambdoid $(\mathrm{n}=10,6 \%)$, and metopic $(\mathrm{n}=22,13 \%)$. Ninety-six of these cases had postoperative head CT scans available for comparison. Follow-up scanning was performed between 9 and 66 months after repair. When including all types of craniosynostosis, neosuture development occurred in $23.9 \%$ of the cases (23 of 96; Table 1). Neosutures were classified as complete or incomplete, as described in the Methods section. Figure 1 displays sample images of complete neosuture in sagittal, lambdoid, and bicoronal synostosis, with pre- and postoperative images for comparison. One can see on the left of each panel the preoperative 3D head CT reconstructions demonstrating fused sutures resulting in craniosynostosis. In comparison, approximately 1 year postoperatively, anatomically normal-appearing neosutures are present in the appropriate orientation and spanning the entire length of the resected sutures. Complete anatomical neosuture formation was seen in 9 of 16 sagittal, 1 of 2 bilateral coronal, 1 of 1 lambdoid, and 3 of 4 unilateral coronal synostosis cases. The complete sagittal neosutures were then used for further study regarding the effect of neosuture formation on postoperative calvarial development.

The mean preoperative CI for cases of sagittal synos- tosis $( \pm$ SEM) was $64.0 \% \pm 2.9 \%$ in non-neosuture cases and $63.5 \% \pm 5.0 \%$ in neosuture cases. The mean postoperative CIs were $77.5 \% \pm 0.6 \%$ (non-neosuture) and $76.6 \%$ $\pm 1.5 \%$ (neosuture). There were no statistically significant effects on postoperative CI from the presence of neosuture formation $(p=0.541)$, age at surgery $(p=0.779)$, or preoperative CI ( $\mathrm{p}=0.156$; Table 2$)$. Overall, the regression model only accounted for approximately $5 \%$ of the variation in postoperative $\mathrm{CI}\left(\mathrm{R}^{2}=0.051\right)$. Only cases with complete pre- and postoperative data sets were included in the model $(n=56)$.

\section{Discussion}

The literature remains sparse on the fate of the synostotic suture after surgery. The appearance of radiologically normal-appearing cranial sutures of a patient who had undergone coronal and parasagittal craniectomies was first noted by Shillito. ${ }^{20}$ The neosutures were discovered 7 months after surgery and were still present up to 5 years 5 months postoperatively. Since then, there has only been a handful of papers describing this phenomenon. ${ }^{1,5,17,20}$

In this study, we present the rate of neosuture formation after endoscope-assisted strip craniectomy and postoperative orthotic therapy of craniosynostosis in 96 children. We found the overall rate of neosuture formation to be $23.9 \%$ for all the sutures combined. The largest previous study ${ }^{1}$ that reported on neosuture formation identified a rate of $16.7 \%$ ( 7 of 42 patients) suture re-formation of sagittal synostosis after open craniectomy cases. In our co-
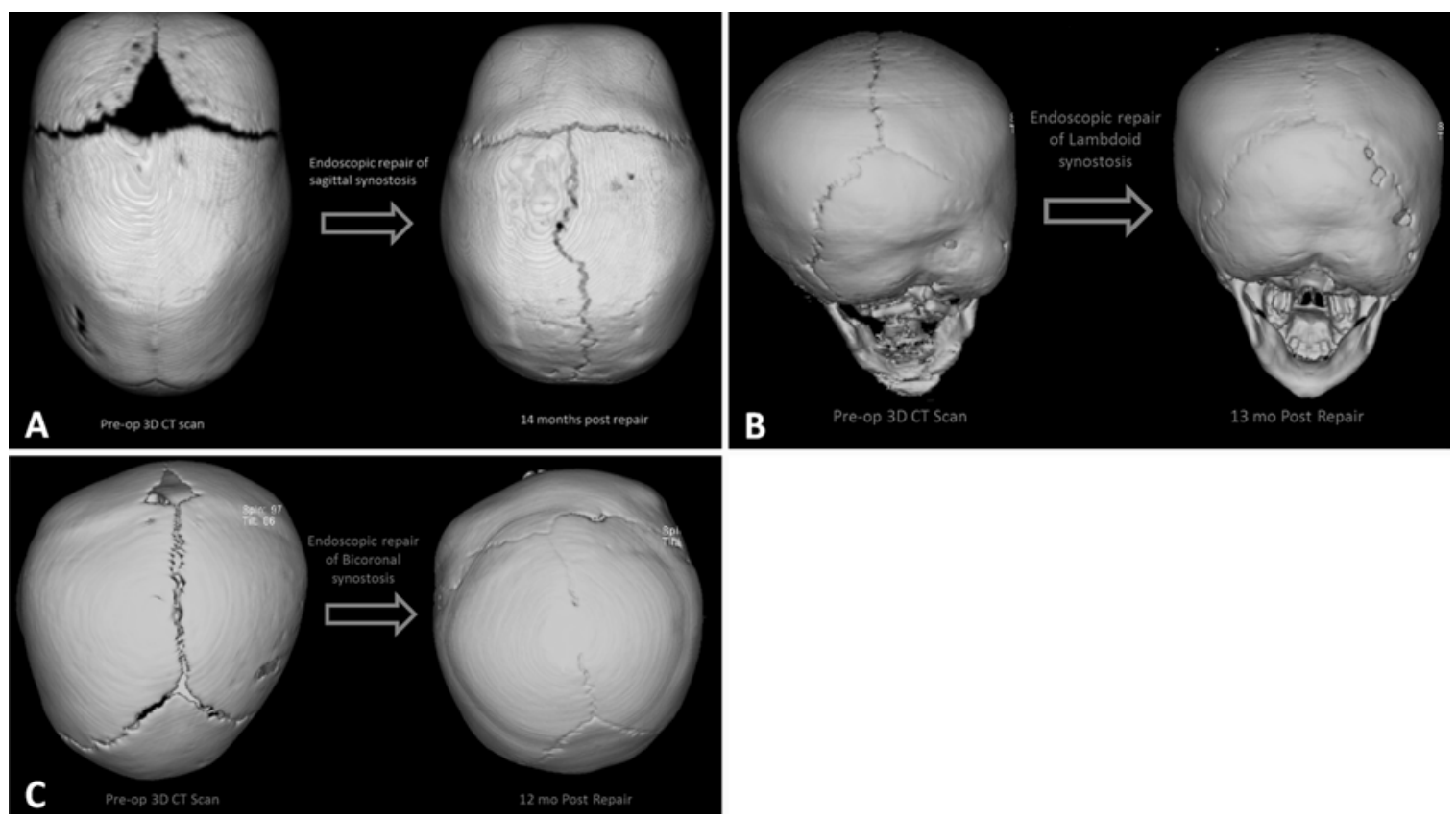

FIG. 1. Sample 3D CT images of complete neosuture in sagittal, lambdoid, and bicoronal synostosis with pre- and postoperative images for comparison. A: A preoperative scan showing the fused sagittal suture with the resultant scaphocephaly (left). The base of the skull has been subtracted for better visualization of the calvaria. The scan on the right was obtained in the same patient 14 months after she underwent endoscope-assisted repair of the synostosis and shows evidence of re-formation of a complete sagittal neosuture spanning from the coronal sutures to the lambdoid sutures in an anatomically correct location and orientation. The extent of the strip craniectomy is evident as an area of paramedian thinning of the bone. B: Preoperative and postoperative scans showing re-formation of complete lambdoid neosuture 13 months after repair. C: Preoperative and postoperative scans showing a case of neosuture formation 12 months after repair of bicoronal synostosis. 
TABLE 2. Linear regression analysis results determining the effects of covariates on the dependent variable, postoperative cephalic index ${ }^{*}$

\begin{tabular}{lccc}
\hline \multicolumn{1}{c}{ Covariate } & Effect Size & $\begin{array}{c}\text { 95\% Confidence } \\
\text { Interval }\end{array}$ & p Value \\
\hline Presence of neosuture & -0.88 & -3.70 to 1.98 & 0.541 \\
\hline Age at op & -0.18 & -1.55 to 1.18 & 0.779 \\
\hline Preop cephalic index & -0.05 & -0.12 to 0.19 & 0.156 \\
\hline
\end{tabular}

* Effect size and $95 \%$ confidence interval values are percentages.

hort of 73 sagittal synostosis cases, we found this rate to be $21.9 \%$. Among other factors, this slight difference may be partly related to the open craniectomy technique used in the mentioned study ${ }^{1}$ versus the endoscope-assisted method that was used by our group.

In addition, Agrawal et al. ${ }^{1}$ used plain radiographs in their study for the identification of neosutures, whereas CT scans were used in our study. Identification of neosutures is more difficult via plain radiography, which may have played a role in the underestimation of this phenomenon by Agrawal's group. Furthermore, our cohort is larger than that of their study, and our measured rate of neosutures includes complete and incomplete neosutures seen postoperatively.

The etiology of neosuture formation may, in part, be related to the pathogenesis of craniosynostosis. Competing theories exist to explain the cause of craniosynostosis: Moss's hypothesis ${ }^{15}$ describes a primary abnormality at the cranial base, whereas Babler ${ }^{2}$ hypothesizes that the abnormality is in the affected calvarial sutures themselves. In syndromic craniosynostosis, it is thought that the primary defect of the cranial base is the culprit for alteration of dural reflections and thereby predisposition to premature sutural closure. ${ }^{13}$ To that end, because surgery does not correct the cranial base abnormality, it is not surprising that resynostosis occurs more frequently in syndromic craniosynostosis compared with nonsyndromic craniosynostosis. McCarthy et al. demonstrated a $13.5 \%$ reoperation rate for nonsyndromic and $36.8 \%$ rate for syndromic craniosynostosis. ${ }^{12}$ In contrast, in nonsyndromic cases, some attribute synostosis to intrauterine forces acting on individual sutures. ${ }^{2}$ More recent studies, however, suggest that more likely there are genetic factors such as TWIST, RUNX2, or other genetic mutations that play a role in nonsyndromic single-suture synostosis. ${ }^{13,18}$ In comparison, in nonsyndromic cases, surgery does correct the underlying pathology by removing the involved suture, which may explain the lower rate of resynostosis. This also, at least partly, explains the development of a neosuture after resection of a fused suture. Surgical correction removes the involved fused suture, and in the absence of cranial base abnormality, new sutures may reform, resembling a normal suture. This hypothesis is further supported by animal studies, which have shown that in the event of excision and disposal of the calvaria, new calvaria re-forms with sutural development in their normal anatomical positions..$^{10,11}$

We identified a $24 \%$ rate of neosuture formation but did not find any dominant predictive factor. Thus, multiple factors affecting neosuture formation are at play. For instance, it is not known whether the use of postoperative helmet therapy has any effect on this process or might even contribute to delayed synostoses of affected or even uninvolved sutures ${ }^{23}$ It is interesting to note, however, that in our cohort of endoscopically treated craniosynostosis with helmet therapy for 6-9 months, we did not see suture re-fusion. An additional factor potentially affecting our observed finding may have been the operative technique. In animal studies with observed neosuture formation, it is suggested that maintenance of dural integrity during the operation and reestablishment of pericranial continuity postoperatively are essential for the formation of neosutures. ${ }^{10}$ The surgical techniques used in this study preserved the dura, but the pericranium was disrupted over the suturectomy site to a varying extent.

In addition, we measured the CI of pre- and postsurgical repair in children who developed neosutures and those who did not for comparison of calvarial shape. There are several limitations in this study. In our small sample, we found no significant difference between the CI of the neosuture and fused suture groups at an average of 17 months after surgery. It is unknown whether longer follow-up would uncover some anatomical differences, as it has previously been shown that the original dysmorphology may return. ${ }^{3,22}$ It would be interesting to see if patients with neosutures have improved cranial morphology in the long term. Certainly, further studies must be carried out to better characterize the neosutures with a longer-term follow-up and with a larger sample size. Additional studies to compare neosuture phenomena in endoscope-assisted versus open calvarial vault reconstruction are needed.

\section{Conclusions}

This study reports the rate of formation of neosutures after endoscope-assisted repair of craniosynostosis. We investigated the rate of this phenomenon and report that there appears to be no statistically significant difference in CI measurements at 17 months postoperatively. Further studies are needed to investigate the long-term effects of neosuture formation on calvarial growth and head shape.

\section{References}

1. Agrawal D, Steinbok P, Cochrane DD: Reformation of the sagittal suture following surgery for isolated sagittal craniosynostosis. J Neurosurg 105 (2 Suppl):115-117, 2006

2. Babler WJ, Persing JA, Winn HR, Jane JA, Rodeheaver GT: Compensatory growth following premature closure of the coronal suture in rabbits. J Neurosurg 57:535-542, 1982

3. Fearon JA, Ruotolo RA, Kolar JC: Single sutural craniosynostoses: surgical outcomes and long-term growth. Plast Reconstr Surg 123:635-642, 2009

4. Jimenez DF, Barone CM: Endoscopic craniectomy for early surgical correction of sagittal craniosynostosis. J Neurosurg 88:77-81, 1998

5. Kinsella CR Jr, Cray JJ, Cooper GM, Pollack IF, Losee JE: Parasagittal suture after strip craniectomy. J Craniofac Surg 22:66-67, 2011

6. Kolar JC: An epidemiological study of nonsyndromal craniosynostoses. J Craniofac Surg 22:47-49, 2011

7. Lajeunie E, Le Merrer M, Bonaïti-Pellie C, Marchac D, Renier D: Genetic study of nonsyndromic coronal craniosynostosis. Am J Med Genet 55:500-504, 1995 
8. Lane LC: Pioneer craniectomy for relief of mental imbecility due to premature sutural closure and microcephalus. JAMA 267:230-230, 1992

9. Lenton KA, Nacamuli RP, Wan DC, Helms JA, Longaker MT: Cranial suture biology. Curr Top Dev Biol 66:287-328, 2005

10. Mabbutt LW, Kokich VG: Calvarial and sutural re-development following craniectomy in the neonatal rabbit. J Anat 129:413-422, 1979

11. Mabbutt LW, Kokich VG, Moffett BC, Loeser JD: Subtotal neonatal calvariectomy. A radiographic and histological evaluation of calvarial and sutural redevelopment in rabbits. J Neurosurg 51:691-696, 1979

12. McCarthy JG, Glasberg SB, Cutting CB, Epstein FJ, Grayson $\mathrm{BH}$, Ruff G, et al: Twenty-year experience with early surgery for craniosynostosis: I. Isolated craniofacial synostosis-results and unsolved problems. Plast Reconstr Surg 96:272-283, 1995

13. Mefford HC, Shafer N, Antonacci F, Tsai JM, Park SS, Hing $\mathrm{AV}$, et al: Copy number variation analysis in single-suture craniosynostosis: multiple rare variants including RUNX2 duplication in two cousins with metopic craniosynostosis. Am J Med Genet A 152A:2203-2210, 2010

14. Mendonca DA, Naidoo SD, Skolnick G, Skladman R, Woo AS: Comparative study of cranial anthropometric measurement by traditional calipers to computed tomography and three-dimensional photogrammetry. J Craniofac Surg 24:1106-1110, 2013

15. Moss ML, Young RW: A functional approach to craniology. Am J Phys Anthropol 18:281-292, 1960

16. Nguyen DC, Patel KB, Skolnick GB, Naidoo SD, Huang AH, Smyth MD, et al: Are endoscopic and open treatments of metopic synostosis equivalent in treating trigonocephaly and hypotelorism? J Craniofac Surg 26:129-134, 2015

17. Sauerhammer TM, Seruya M, Ropper AE, Oh AK, Proctor MR, Rogers GF: Craniectomy gap patency and neosuture formation following endoscopic suturectomy for unilateral coronal craniosynostosis. Plast Reconstr Surg 134:81e-91e, 2014

18. Seto ML, Hing AV, Chang J, Hu M, Kapp-Simon KA, Patel $\mathrm{PK}$, et al: Isolated sagittal and coronal craniosynostosis as- sociated with TWIST box mutations. Am J Med Genet A 143A:678-686, 2007

19. Shah MN, Kane AA, Petersen JD, Woo AS, Naidoo SD, Smyth MD: Endoscopically assisted versus open repair of sagittal craniosynostosis: the St. Louis Children's Hospital experience. J Neurosurg Pediatr 8:165-170, 2011

20. Shillito J: A new cranial suture appearing in the site of craniectomy for synostosis. Radiology 107:83-88, 1973

21. Slater BJ, Lenton KA, Kwan MD, Gupta DM, Wan DC, Longaker MT: Cranial sutures: a brief review. Plast Reconstr Surg 121:170e-178e, 2008

22. Wes AM, Paliga JT, Goldstein JA, Whitaker LA, Bartlett SP, Taylor JA: An evaluation of complications, revisions, and long-term aesthetic outcomes in nonsyndromic metopic craniosynostosis. Plast Reconstr Surg 133:1453-1464, 2014

23. Yarbrough CK, Smyth MD, Holekamp TF, Ranalli NJ, Huang AH, Patel KB, et al: Delayed synostoses of uninvolved sutures after surgical treatment of nonsyndromic craniosynostosis. J Craniofac Surg 25:119-123, 2014

\section{Disclosures}

Dr. Patel reports being a consultant for Stryker CMF and a speaker for Hanger Clinic.

\section{Author Contributions}

Conception and design: Salehi, Kane, Woo, Patel, Smyth. Acquisition of data: Salehi, Ott, Naidoo. Analysis and interpretation of data: Salehi, Ott, Skolnick, Patel, Smyth. Drafting the article: Salehi, Ott, Nguyen, Woo. Critically revising the article: Salehi, Patel, Smyth. Reviewed submitted version of manuscript: all authors. Approved the final version of the manuscript on behalf of all authors: Salehi. Statistical analysis: Salehi, Skolnick. Study supervision: Woo, Patel, Smyth.

\section{Correspondence}

Afshin Salehi, Department of Neurological Surgery, Washington University School of Medicine, Campus Box 8057, 660 S Euclid Ave., St. Louis, MO 63110.email: salehia@wudosis.wustl.edu. 